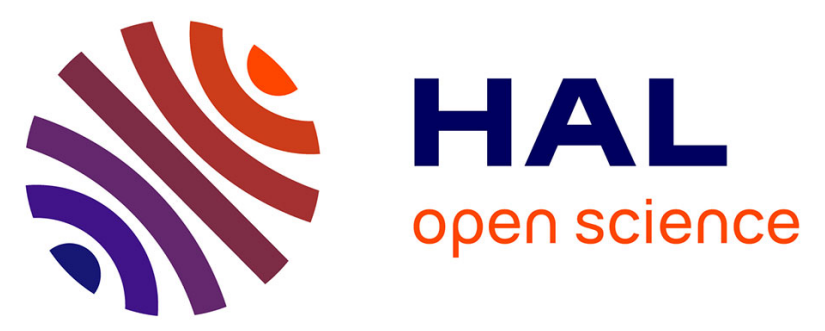

\title{
Identification of non uniform thermal contact resistance in automated tape placement process
}

\author{
Anaïs Barasinski, Adrien Leygue, Eric Soccard, Arnaud Poitou
}

\section{To cite this version:}

Anaïs Barasinski, Adrien Leygue, Eric Soccard, Arnaud Poitou. Identification of non uniform thermal contact resistance in automated tape placement process. International Journal of Material Forming, 2013, 7 (4), pp.479-486. 10.1007/s12289-013-1144-9 . hal-01006940

\section{HAL Id: hal-01006940 \\ https://hal.science/hal-01006940}

Submitted on 8 Feb 2017

HAL is a multi-disciplinary open access archive for the deposit and dissemination of scientific research documents, whether they are published or not. The documents may come from teaching and research institutions in France or abroad, or from public or private research centers.
L'archive ouverte pluridisciplinaire HAL, est destinée au dépôt et à la diffusion de documents scientifiques de niveau recherche, publiés ou non, émanant des établissements d'enseignement et de recherche français ou étrangers, des laboratoires publics ou privés. 


\section{Identification of non uniform thermal contact resistance in automated tape placement process}

\section{Anaïs Barasinski • Adrien Leygue • Eric Soccard · Arnaud Poitou}

A. Barasinski · A. Leygue · A. Poitou GeM Institute, Ecole Centrale de Nantes,

1 rue de la Noe, 44321 Nantes cedex 3, France

e-mail: anais.barasinski@ec-nantes.fr

E. Soccard

EADS-IW, Rue Belouga,

44300 Bouguenais, France

e-mail: eric.soccard@eads.net deposition velocity. The ability to manufacture large, complex shaped and thin laminated parts makes it suitable for aeronautical applications or wind turbine blades. The deposition of up to $60 \mathrm{~m}^{2}$ of material per hour has been achieved $[1,2]$.

The ATP process involves a mould and a deposition head. The deposition head comprises a heating source and a compaction system. A possible configuration consisting in a laser beam and two rollers and corresponding to the configuration used in this work is depicted in Fig. 1. The principle of the process is to lay down successive layers of material by welding with the deposition head an incoming tape on a substrate. This process is already well developed for thermosets materials and is divided in two steps: a laying step and a curing step. Recent technology developments aim at adapting this process to thermoplastic matrix composite materials, and develop a one step process by reaching in-situ consolidation of the material during the deposition step [3].

In order to reach in-situ consolidation with this process, the material has to undergo the several steps depicted in Fig. 1: heating, consolidation, and cooling. During these three stages, different physical phenomena occur:

- The heating step allows the matrix fusion which is a prerequisite for adhesion.

- In the consolidation step, the interply adhesion takes place. This is also where the final porosity level is fixed. At the molecular scale, the interply adhesion of the thermoplastic matrix is achieved through the reptation of the polymeric macromolecules [4].

- During the cooling step the crystallization of the polymer matrix might occur if the cooling rate is appropriate [5]. 


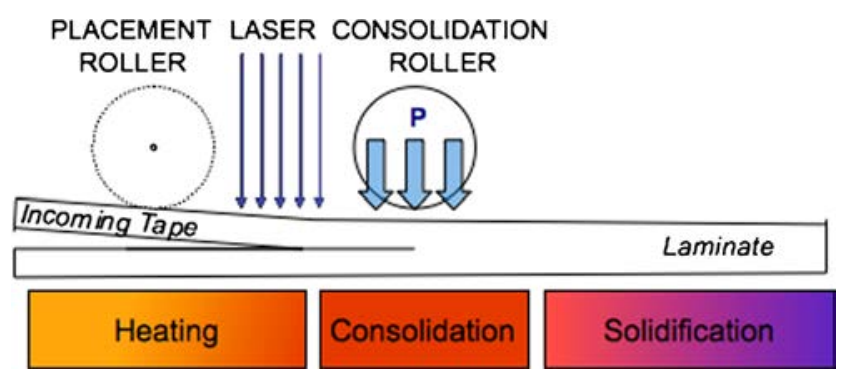

Fig. 1 Schematic configuration of the ATP placement head and corresponding steps of the process

The first heating step is crucial because the material is a semi-crystalline thermoplastic material. Indeed, on one hand, if the crystalline phase does not fuse, the adhesion is compromised. On the other hand, the matrix is not thermally stable: chain branching, and crosslinking occur at high temperature and lead to the thermal degradation of the matrix $[6,7]$. This must be avoided at any price: if the matrix is degraded, the adhesion isn't possible anymore. For a given material and roller, only the heat source and placement velocity play significant roles in this first step of heating to ensure fusion and avoid degradation. The consolidation step starts when the roller enters the heated zone and the compaction force is applied. The intimate contact between the two plies is achieved and interply adhesion takes place [8]. From the combination of temperature and pressure, a micro matrix flow can occur, and intraply porosities [9] can evolve.

As we can clearly understand, this process is complex because of the many different parameters that come into play. The different physical phenomena have to occur at the right time, and in the right order. Moreover, the important point is that all these phenomena take place at material interfaces and are governed by temperature. It is therefore critical to understand and control the evolution of the temperature field in the whole part during the forming steps. In this work, we develop a numerical model allowing the accurate prediction of the temperature field for this process. The key ingredient is the introduction of thermal contact resistances (TCR) to model the non perfect thermal transfer from one ply to the other.

Although the material is not homogeneous, one can reasonably assume homogenized thermal properties at the scale of the ply. This assumption does not hold at the scale of the laminate as conduction depends on the degree of intimate contact between the plies and is therefore imperfect [10]. This is why we postulate interply TCR: the vertical heat flux between two plies is proportional to the temperature difference between the two sides of the interface. For a deeper analysis of the interply thermal resistance the interested reader can refer to [11].

This hypothesis and the resulting thermal model are validated through the comparison between experimental and numerical results. The comparison shows the existence of TCR and the importance of taking them into account for the quantitative prediction of the temperature in the adhesion zone.

In the following sections, the experimental and numerical tools are first presented. Then, experimental results are analyzed to highlight the TCR existence. Finally we show the predictive capabilities of the model.

\section{Material, method and model description}

\section{Temperature measurements}

In order to carry out this study, we use a tape placement machine, located in the Technocampus EMC2, in Bouguenais, near Nantes (France).

The machine, called 'Banc 1D', is a prototype bench developed by EADS IW. This system allows laser assisted unidirectional draping of 8 tapes in parallel. The heat source is applied on the upper surface of the laminate to generate adhesion at the interface. The heat source is located between two rollers: the first roller is located before the laser and ensures the contact between the incoming tape and the substrate while the compaction roller is located after the laser, see Fig. 1. The laser system used is a continuous wave solid state laser manufactured by the TRUMPF Company. It has a wavelength of $1064 \mathrm{~nm}$, and a maximum power of $4 \mathrm{~kW}$. An optic system is mounted on the laser head to create a rectangular laser sheet of $50 \times 25 \mathrm{~mm}$ cross section.

The material is a prepreg tape material (APC2) supplied by Cytec. APC 2 consists approximately of $60 \%$ impregnated carbon fibers in a PEEK matrix. The matrix has a fusion temperature of $T_{f} \approx 340^{\circ} \mathrm{C}$ and a glass transition temperature of $T_{g}=143^{\circ} \mathrm{C}$ [12]. The homogenized thermal properties are reported in Table 1, where $K_{x x}$ and $K_{z z}$ are the longitudinal and transverse conductivities. The tapes have a thickness of $0.135 \mathrm{~mm}$ and a corresponding width of $6.35 \mathrm{~mm}$.

A unidirectional laminate made of 6 layers is manufactured and thermal acquisition is performed using $\mathrm{K}$ type thermocouples positioned at the ply interfaces, as depicted in Fig. 4. A diameter inferior to $100 \mu \mathrm{m}$ has been chosen in order to limit their intrusivity. The laser power is fixed at $1000 \mathrm{~W}$, and the deposition velocity $v=5 \mathrm{~m} \mathrm{~min}^{-1}$.

Table 1 Homogenized thermal properties of the APC2 tape material used in the model [12]

\begin{tabular}{llll}
\hline$\rho\left(\frac{\mathrm{kg}}{\mathrm{m}^{3}}\right)$ & $C_{p}\left(\frac{\mathrm{J}}{\mathrm{kg} \mathrm{K}}\right)$ & $K_{x x}\left(\frac{\mathrm{W}}{\mathrm{mK}}\right)$ & $K_{z z}\left(\frac{\mathrm{W}}{\mathrm{mK}}\right)$ \\
1560 & 1700 & 5 & 0.5 \\
\hline
\end{tabular}


Figure 5 (left) shows a typical measurement set for three sensors positioned at the three upper interfaces.

One directly foresees that this type of measurements somehow contradicts the hypothesis of the existence of TCR. Indeed, the sensors measure only one interface temperature while we postulate that the interface heat flux depends on the temperature jump a the interface. We will therefore assume that the measured temperature is the average of the surface temperatures of the two plies at the interface. As strong as this hypothesis might seem, it does not affect the qualitative analysis to prove the existence of evolving TCR and the very good quantitative agreement with the simulation will validate the assumption that the measured temperature is some average of the plies surface temperatures.

\section{The heat transfer model}

In the numerical model, we choose to neglect the effects of thermal degradation and crystallization of the PEEK matrix. These phenomena would modify the thermal properties of the material, but because of the considered time scales and of the importance of the laser source with respect to other thermal phenomena, we can use constant material parameters.

Although the process is transient from the point of view of the laminate, we can simplify its modeling, far from the edges, by computing a steady state solution of the heat transfer problem in a euclidian reference frame attached to the laser. In this frame, the deposition head is fixed while the laminate is moving under the laser spot. Furthermore we consider that as we are manufacturing huge parts, it is reasonable to consider that the incoming substrate has had the time to reach thermal equilibrium since its last exposition to the laser.

As all the plies are oriented along the same direction, parallel to the deposition direction, the symmetry of the problem allows us to solve the $2 \mathrm{D}$ case only. Within each ply we solve the following heat transfer problem:

$\rho C_{p}(v \cdot \nabla T)=\nabla \cdot K \cdot \nabla T$,

where $\mathbf{T}$ is the temperature, $\rho$ is the volumetric mass, $C_{p}$ is the heat capacity, $\mathbf{K}$ is the anisotropic conductivity tensor, and $v$ is the velocity of the laminate with respect to the laser spot. The vertical heat flux between two plies labelled $i$ and $j$ is modeled as follows:

$q_{Z i j}(x, t)=\frac{1}{R_{t h, i j}(x)} \times\left[T_{j}^{+}(x, t)-T_{i}^{-}(x, t)\right]$,

where $q_{Z}$ is the normal heat flux, $R_{t h, i j}(x)\left(\mathrm{K} \mathrm{m}^{2} \mathrm{~W}^{-1}\right)$ is the value of the thermal resistance between plies $i$ and $j$, and $T_{i}$ and $T_{j}$ respectively are the temperature in the two layers at the considered interface.

In order to assess the importance of the TCR we will consider three different models for the parameter $R_{t h, i j}(x)$ and its $x$-dependence. These three models are illustrated in Fig. 2.

- The first and simplest model (Fig. 2 top right), consists in neglecting the TCR between plies. We consider the heat transfers are perfect and there is consequently no temperature discontinuity from one ply to the next.

- The second model (Fig. 2 bottom left) assumes a nonzero but constant TCR along $\mathrm{x}$. We consider poor heat transfers between plies that are not influenced by the changes occurring at the interface when heated and compacted.

- The third model (Fig. 2 bottom right) assumes that the healing process taking place during the compaction of the plies by the roller improves the quality of the heat transfer. Consequently we consider a piecewise constant value for $R_{t h, i j}(x)$, which decreases each time the interface is heated and compacted. From the experimental measurements presented below in Fig. 5 (left), we observe that the temperature at the third interface is too low (w.r.t $T_{g} \& T_{f}$ ) to induce any significant change of the interface upon compaction. Consequently we consider the RTC to be constant from the third interface on.

The heating source is modeled as a surface heat flux with a gaussian distribution, applied on the upper face of the top ply. The flux boundary conditions with the mould, the roller and the air are modeled as the heat transfers at the interface between two plies but with fixed temperatures for those external elements. The values of all transfer coefficients are taken from the literature [12-14] while details of the boundary conditions are reported in Fig. 3. The numerical solution of the model is computed using the Proper Generalized Decomposition (PGD) method [15] using a separation of the $\mathrm{x}$ and $\mathrm{z}$ coordinates. The solution is sought under the following separated form:

$T(x, z)={ }_{i}^{N} X_{i}(x) \times Z_{i}(z)$.

This method has proved its efficiency for computing thermal and elasticity problems in such thin geometries [16-18] where it allows the use of a very thin mesh in the thickness direction while maintaining reasonable computation times. Along the deposition direction we did simulate a length of $0.5 \mathrm{~m}$ discretized with 1000 finite elements while in the thickness direction we have 6 plies of $0.135 \mathrm{~mm}$, each discretized using 20 elements. The solution procedure is 
Fig. 2 Description of the three models of thermal contact resistance $\left(\mathrm{K} \mathrm{m}^{2} \mathrm{~W}^{-1}\right)$ at the different interfaces

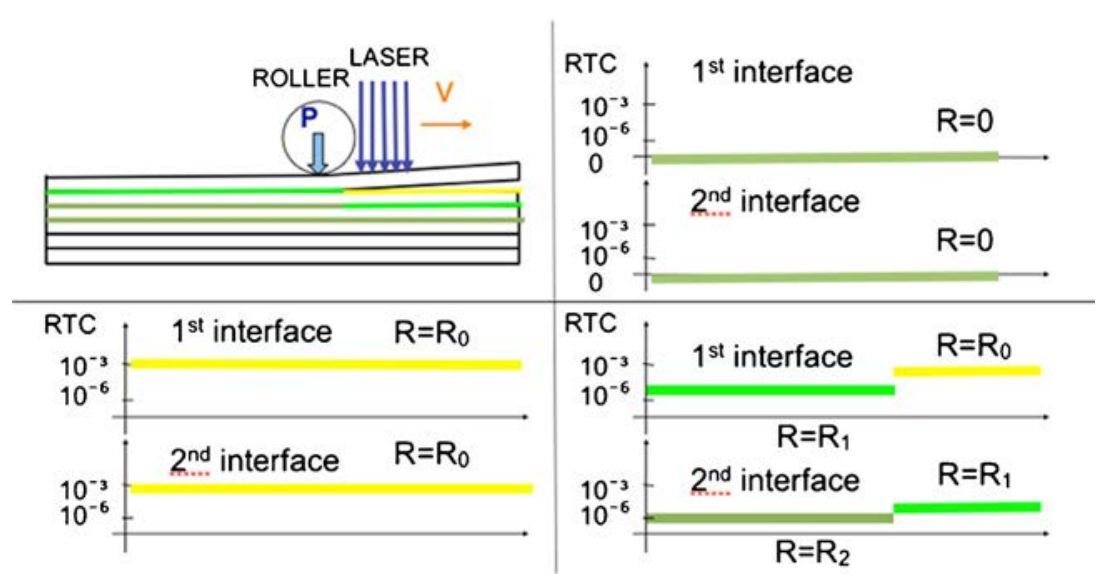

implemented in a homemade Matlab ${ }^{\circledR}$ code and takes only a few seconds to run on a simple laptop computer.

\section{Experimental highlighting of the existence of TCR}

In order to assess the quality of the thermal contact between the layers and its evolution during the process, we used the following set up: First, several prepreg layers are deposited on the laminate part, with thermocouples at the interfaces, as shown in Fig. 4. The temperature is recorded using the thermocouples during the deposition of the last layer. Then, an additional consolidation step is performed with the placement head, during which the laminate is heated and compacted but no ply is added to the part. The temperature is again recorded during this step. The measurements for both steps are reported in Fig. 5.

As we can observe in Fig. 5, the temperature profiles of the last deposition step and of the consolidation step are very different while the thermal properties of the material have not changed. During the last deposition step, the temperature, reaches about $330{ }^{\circ} \mathrm{C}$ at the first interface, $170{ }^{\circ} \mathrm{C}$

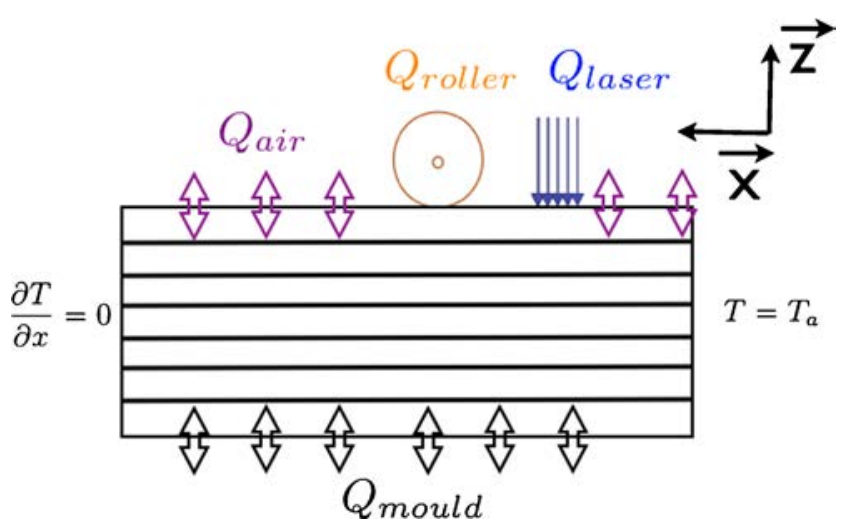

Fig. 3 Detail of the boundary conditions of the thermal model at the second and $130{ }^{\circ} \mathrm{C}$ at the third while during the consolidation step, the temperature at the three first interfaces are respectively about $260{ }^{\circ} \mathrm{C}, 200{ }^{\circ} \mathrm{C}$, and $150{ }^{\circ} \mathrm{C}$. A simple interpretation is that during the deposition pass, the heat is confined in the first layer, because the thermal contact is of poor quality, but during the consolidation pass, the bonding is better, so is the thermal contact. The heat can flow more easily through the substrate, making the temperature lower at the first interface, but therefore significantly higher at the next two interfaces. The only quantity capable of inducing such changes between the two passes are the interface characteristics which in our model corresponds to the RTC.

These measurements point towards the existence of an imperfect thermal contact between the different layers of the laminate which evolves during heating and compaction. These hypothesis will be validated later using the numerical model.

\section{Influence of TCR values on the thermal field}

As shown above, the healing and the degree of thermal contact between the different layers of the laminate evolves during the process, and has a significant influence on heat transfer. Using the numerical tool and model presented in Section "The heat transfer model", we simulate the temperature field in a laminate part during the process for the three different models of RTC (Fig. 2), but keeping material and process parameters constant. The simulation results are shown in Fig. 6.

One can observe that in the first case (Fig. 6, top left), i.e. no TCR taken into account, the temperature field is continuous, and the maximum value of the temperature is about $400{ }^{\circ} \mathrm{C}$. In the second case (Fig. 6, top right), i.e. taking a constant value of the TCR, the thermal field becomes discontinuous. More precisely, there are discontinuities in the 

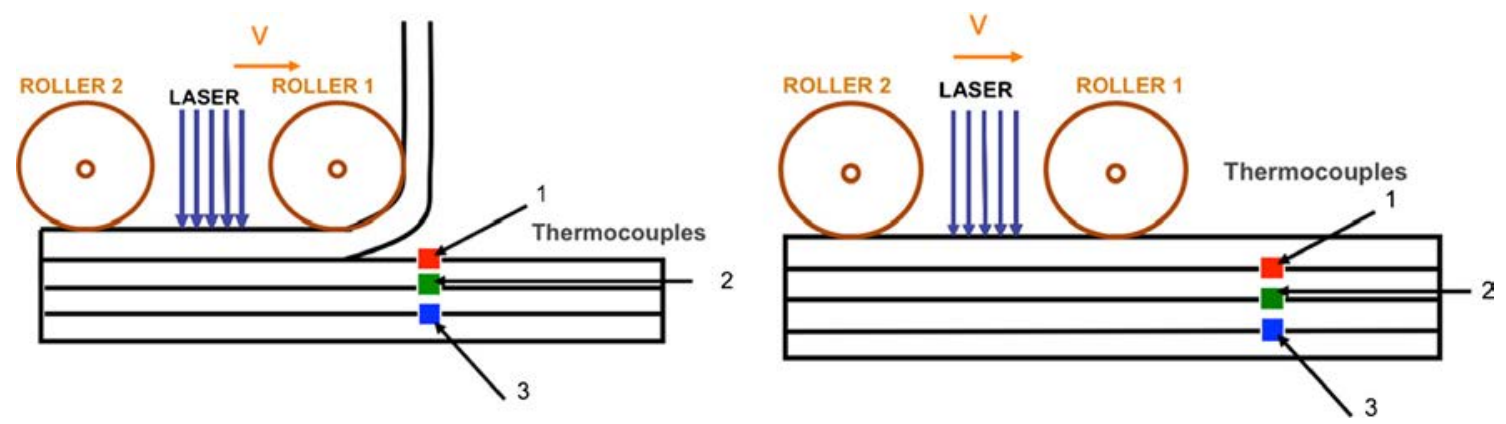

Fig. 4 Localization of the sensors during de deposition pass (left) and additional pass (right)

temperature between each ply. In that case the maximum temperature in the laminate reaches $600{ }^{\circ} \mathrm{C}$ as most of the energy is concentrated in the first ply and flows poorly to the next plies. Finally in the third case (Fig. 6, bottom), i.e. taking into account an evolving value of the TCR, the temperature field is still discontinuous, but the discontinuity is localized under the heating source, here the temperature reaches a maximum of $600{ }^{\circ} \mathrm{C}$ as well. Downstream of the laser, as the value of TCR decreases, heat flows further down which yields higher interface temperatures. With this comparison, we can develop a first understanding of the importance of taking into account TCR, and its evolution, in the numerical model of the tape placement process. Considering perfect heat transfers between plies will result in lower temperatures, while taking into account a TCR to model the imperfect thermal contact concentrates the heat in the first ply. This may promote the inter-ply adhesion phenomena, which are strongly driven by temperature.

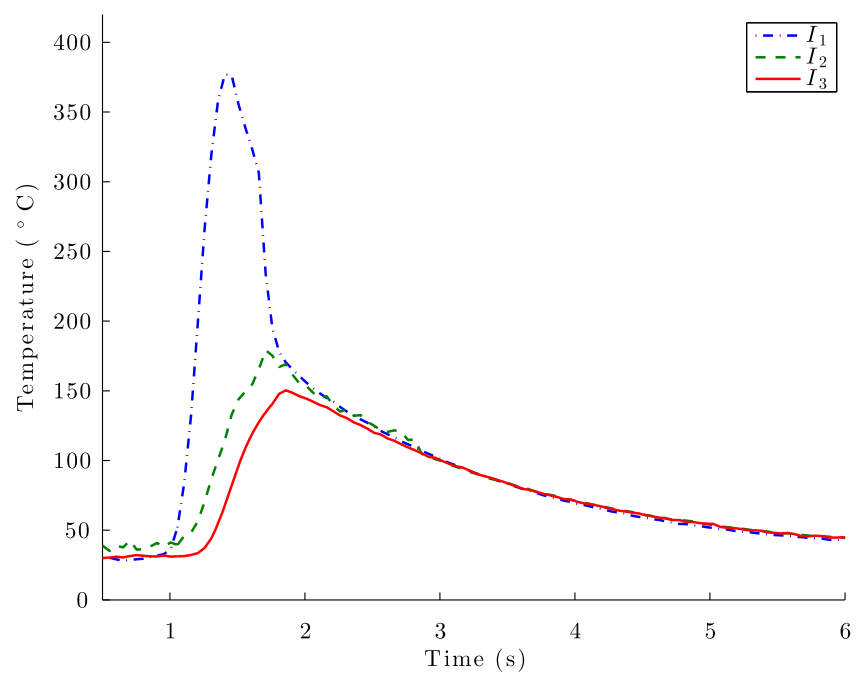

\section{Comparison between experimental and numerical results}

Analysis of the different scenarios

In this section we use the numerical model to identify the values of the thermal contact resistance for the three modeling scenarios presented in Section "The heat transfer model". Starting from an initial guess, the value of the TCR is slightly adjusted to obtain the best possible simultaneous fit for the temperature at the two upper interfaces of the laminate during the deposition of an additional ply. As the presence of TCR induces a discontinuous temperature field at the interface we used for the fitting procedure the average of the two interface temperatures. The results of this procedure are shown in Figs. 7 to 9.

For the first model of TCR, we see in Fig. 7 that because of the important heat transfers through the interfaces the temperature at both interfaces cannot be predicted

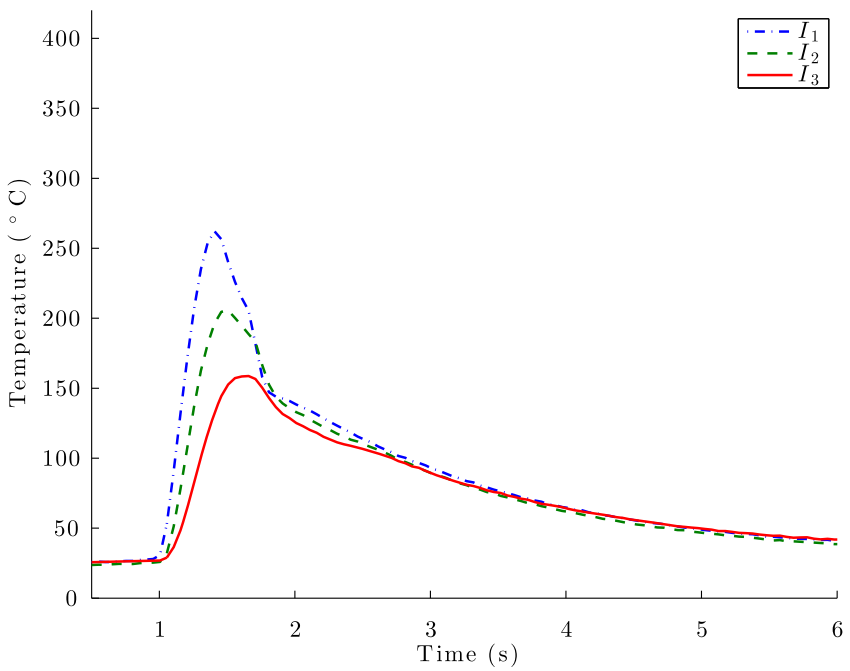

Fig. 5 Measured temperature in the plate during the deposition of last layer (left) and additional pass (right) 
Fig. 6 Steady state temperature field in the reference frame of the deposition head depending on the TCR value. Top left: no TCR, Top right: constant TCR. Bottom: evolving TCR
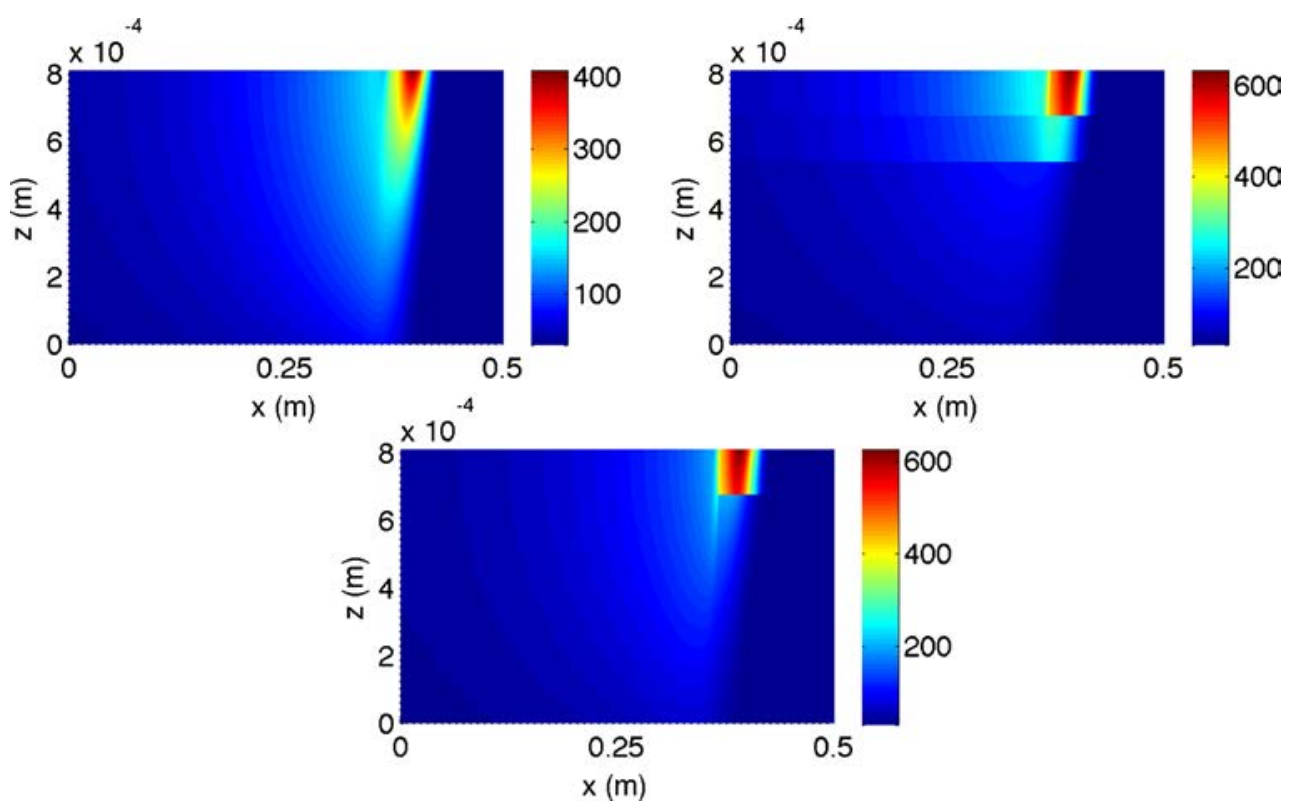

simultaneously. The simulated temperature peak at the first interface is not as high as the recorded one while the second interface temperature is clearly underestimated. Additionally, the slope of the temperature curve at the second interface is qualitatively wrong in the heating phase. The cooling phase however shows a good agreement between experiments and simulation.

For the second model of TCR, we see in Fig. 8 that the heating part in both curves shows an improved qualitative and quantitative agreement between the measured and simulated temperature for both interfaces. Yet, the cooling part exhibits large discrepancies. Clearly, the constant value of TCR concentrates the heat in the first ply, and does not

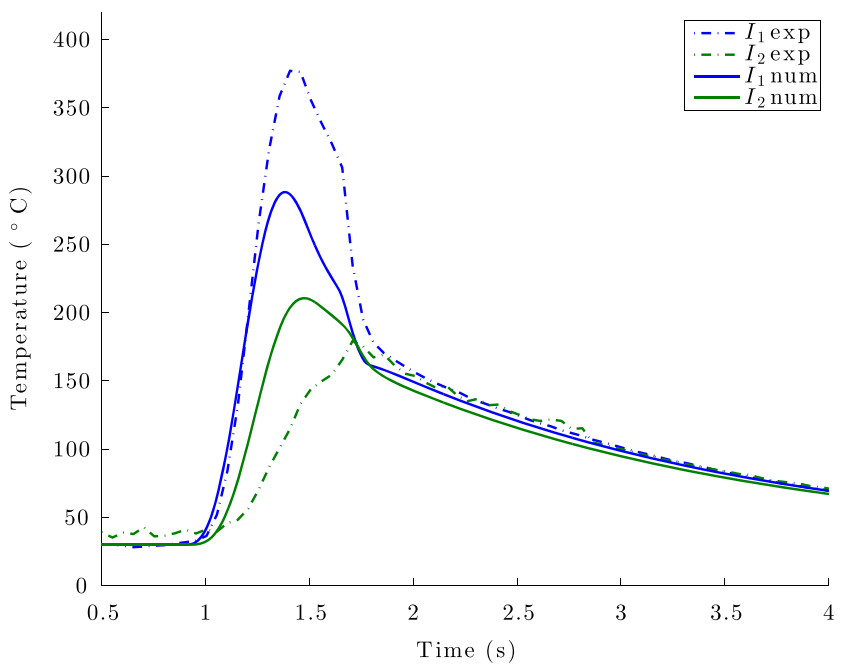

Fig. 7 Comparison of experimental results with numerical ones calculated with a perfect interply thermal contact allow the thermal transfers occurring during the cooling phase.

For the third model of TCR, which accounts for an evolution of TCR, we see in Fig. 9 an overall agreement between experiments and simulations. Both the heating and cooling steps match quantitatively. Furthermore, we see that the numerical tool can predict fine details of the temperature curves such as the slight overshoot at the second interface at the end of the heating phase. This feature is actually caused in the model by the sudden evolution of the TCR under the compaction roller which allows the heat to flow from the first to the second ply. Accounting for an evolving TCR, corresponding to the qualitative evolution of the interply

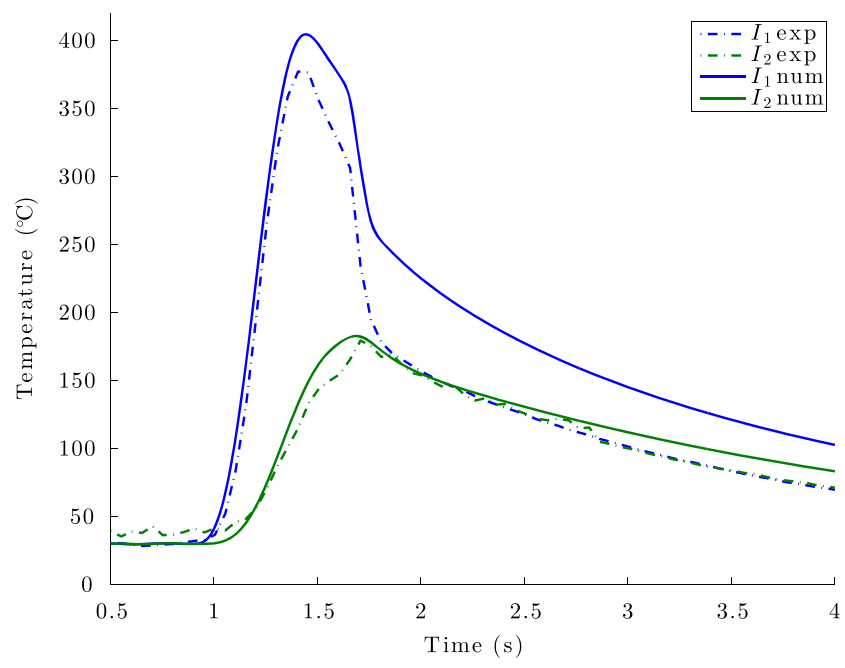

Fig. 8 Comparison of experimental results with numerical ones calculated with a constant TCR 


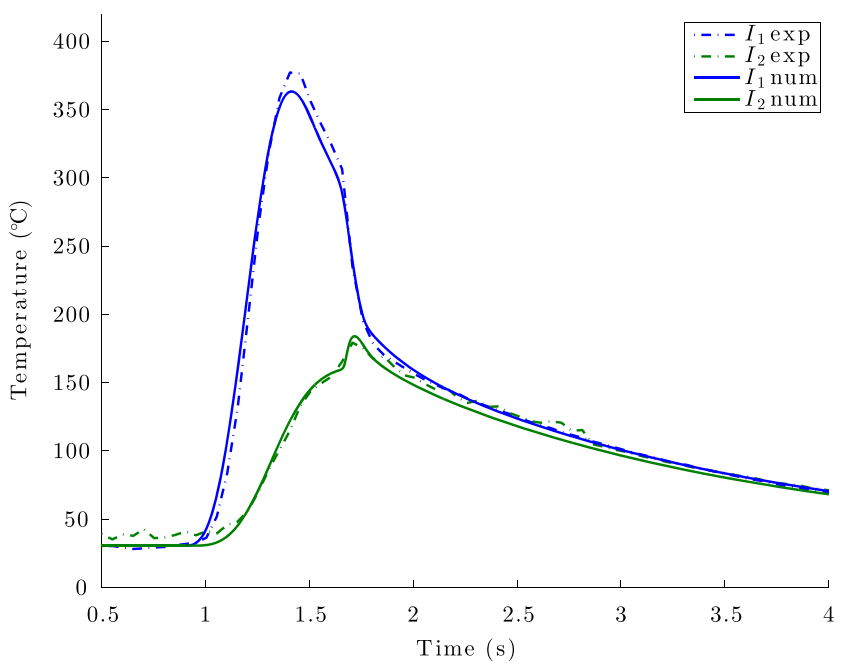

Fig. 9 Comparison of experimental results with numerical ones calculated with an evolving TCR

properties, allows one to have a quantitative prediction of the temperature evolution in the laminate during its manufacturing. Finally in this last scenario, it should be noted that the simulation results are not very sensitive to the exact values of the RTC. The correct magnitude combined to the sudden decrease of the RTC under the compaction roller are enough to obtain a very good fit of the data.

Validation of the thermal model on the consolidation pass

Using the previously identified values of the TCR we validate the model by simulating the consolidation pass described in Section "Experimental highlighting of the existence of TCR". In Fig. 10, we compare the experimental interface temperatures of the three first interfaces with the

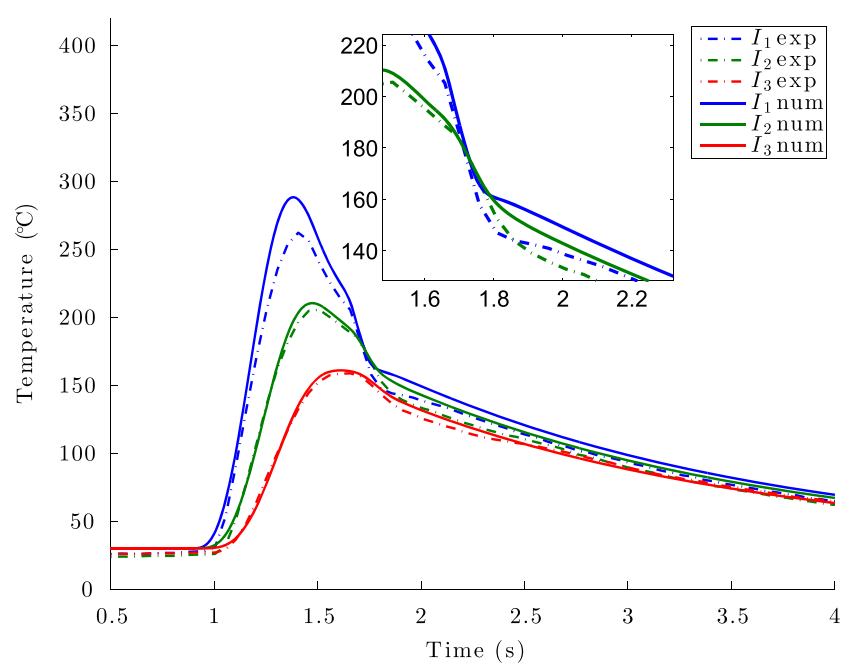

Fig. 10 Comparison of experimental results with numerical ones calculated with an evolving TCR for the consolidation pass numerical predictions. Despite the simplicity of the model and the complexity of the experimental measurements, we find a surprisingly good quantitative agreement between experiments and simulations. The inset shows a detail of the interface temperatures where we observe that, due to the heat flow in the compaction roller, the temperature at the second interface becomes higher than the temperature at the first interface. This experimental feature is correctly predicted by the numerical model. These results suggest that the very good quantitative fit obtained in Fig. 9 does not involve as much over-fitting of the data as one might think and that the model can be used for prediction purposes.

\section{Conclusion}

In this work we presented an experimental and numerical study of the automated tape placement composite forming process applied to thermoplastics. The experiments suggest that degree of interply thermal contact is evolving during the manufacturing of the laminate and that this evolution has a dramatic effect on the thermal transfers in the laminate. We therefore propose a numerical model which accounts for interply thermal contact resistances. The model indeed shows that the value and the evolution of the thermal contact resistance is a critical parameter in order to compute accurate interface temperatures.

In particular we show that it is sufficient to consider that the thermal contact resistance decreases suddenly during the compaction step to quantitatively and accurately predict the experimental results. Moreover the PGD is an appropriate simulation tool for this problem as it allows the high resolution solution of the model in a very short time thanks to the separation of physical coordinates.

These result are very promising for thermal modeling of the automated tape placement process. Further work should focus on the accurate modeling of the heat source and the 3D geometry of the laminate. A more physically detailed model of crystallization, melting and degradation phenomena should also be considered.

\section{References}

1. Hamlyn A, Cartié D, Weber JP (2011) In: 32nd. International conference SEICO 11- New Material Characteristics to cover New Application Needs, Paris

2. Lukaszewicz DHJ, Ward C, Potter KD (2012) Compos: Part B 43:997

3. Schledjewski R (2009) Plast Rubber Compos 38(9-10):379

4. DeGennes P (1971) J Chem Phys 55:572

5. Tierney J, Gillespie J (2004) Compos Part A 35:547

6. Deslandes Y, Boudreau F (1990) J Mater Sci Lett 9:1274

7. Jonas A, Legras R (1991) Polymer 32(15):2691

8. Tierney J, Gillespie J (2006) J Compos Mater 40:1487 
9. Pitchumani R, Ranganathan S, Don R, Gillespie J, Lamontia M (1996) Int J Heat Mass Transf 39(9):1883

10. Barasinski A, Leygue A, Soccard E, Poitou A (2010) AMPT2010

11. Levy A, Heider D, Tierney J, Gillespie J (2013) J Compos Constr. doi: $10.1177 / 0021998313476318$

12. Lamethe JF (2004) Etude de l'adhesion de composites thermoplastiques semi-cristallins; application à la mise en oeuvre par soudage. Ph.D. thesis, Universite Paris VI - Pierre et Marie Curie

13. Nicodeau C (2005) Modélisation du soudage en continu de composites à matrice thermoplastique. Ph.D. thesis, ENSAM Paris
14. Toso Y, Ermani P, Poulikakos D (2004) J Compos Mater 38(2): 107

15. Ammar A, Mokdad B, Chinesta F, Keunings R (2006) J NonNewtonian Fluid Mech 139:153

16. Bognet B, Ghnatios C, Barasinski A, Masson F, Chinesta F, Leygue A, Poitou A (2011) Rev Compos Mater Av 21(1):23

17. Bognet B, Bordeu F, Chinesta F, Leygue A, Poitou A (2012) Comput Methods Appl Mech Eng 201:1

18. Chinesta F, Leygue A, Bognet B, Ghnatios C, Poulhaon F, Bordeu F, Barasinski A, Poitou A, Chatel S, Maison-Le-Poec S (2012) 